\title{
ESTUDOS
}

\section{A definição de número: uma hipótese sobre a hipótese de Piaget}

Clélia Maria Ignatius Nogueira

\section{Resumo}

Nenhum aspecto da matemática foi tão analisado "à luz da teoria piagetiana" quanto o número. Os resultados encontrados por Piaget e Szeminska e publicados no livro $A$ gênese do número na criança geraram, também, inúmeras publicações acerca das suas possíveis implicações pedagógicas. Para os pesquisadores, o número é elaborado a partir da síntese operatória da seriação e da classificação, estabelecendo um tertium entre as definições de número propostas por duas das principais correntes do pensamento matemático: o logicismo e o intuicionismo. Neste artigo expõe-se o debate entre intuicionismo e logicismo sobre o número e a posição epistemológica de Piaget que levou a uma nova concepção de compreender a gênese do número na criança.

Palavras-chave: definição piagetiana de número; logicismo; intuicionismo.

\section{Abstract}

The definition of number: a hypothesis over Piaget's Theory

Perhaps no aspect in Mathematics has been so thoroughly analyzed than the concept of number from Piaget's point of view. Results by Piaget and Szeminska in their book "The Child's Conception of Number" brought forth several publications on possible pedagogical implications on the issue. For researchers, the number concept is worked out from the operational synthesis of serializing and classification, while establishing a tertium between the definitions of number, which have been proposed by two of the main mathematical thoughts, namely logics and intuitionalism. In this article the debate between intuitionalism and logics on the number and Piaget's epistemological stance that led to a new concept on the genesis of number in the child is provided.

Keywords: Piaget's definition of number; logics; intuitionism.

\section{Introdução}

Até 1940, Jean Piaget (1896-1980) já havia analisado as fontes práticas e sensório-motoras do desenvolvimento da criança e publicado seus resultados em duas obras clássicas: $O$ nascimento $d a$ inteligência na criança e A construção do real na criança. Também já havia investigado os aspectos verbais e conceituais do pensamento infantil que resultaram em $A$ formação do símbolo na criança. O próprio Piaget afirma, no prefácio da primeira edição do livro A gênese do número na criança, escrito em 1941, que era necessário "ultrapassar essas duas etapas preliminares e atingir os mecanismos formadores da própria razão", ou seja, 
procurar compreender como os esquemas sensório-motores se organizavam no plano do pensamento em sistemas operatórios, o que, para ele, só seria possível mediante o estudo do número (Piaget; Szeminska, 1981, p. 11).

Do ponto de vista epistemológico, o problema “o que é o número?” intrigou filósofos e matemáticos desde a Antigüidade, evidenciando a existência de um forte contraste entre a clareza instrumental do número e a complexidade das teorias construídas para explicá-lo. Nenhuma das principais correntes do pensamento matemático, como o intuicionismo, o logicismo e o formalismo, até o século 20, conseguiu uma resposta satisfatória para explicar qual a origem do número. Tal desafio interessou a Piaget, para quem somente uma investigação genética poderia conduzir a uma resposta mais conclusiva.

Assim como a verdade técnica da aritmética está fora de toda discussão, a questão de se saber o que é o número deixa evidente a surpreendente incapacidade do pensamento para apreender qual é a natureza de certos instrumentos nos quais, entretanto, acredita compreender completamente e os utiliza em quase todos os seus atos.

Este contraste entre a evidência instrumental do número e a confusão das teorias epistemológicas para explicá-lo deixa claro a necessidade de uma investigação genética: o desconhecimento do pensamento em relação às engrenagens essenciais de seu próprio mecanismo é, com efeito, o índice psicológico de seu caráter elementar e, em conseqüência, da necessidade de se remontar aos primórdios de sua formação para poder alcançá-las (Piaget, 1975, p. 67-68).

Piaget, em parceria com Alina Szeminska, realizou esta investigação genética; os resultados obtidos foram relatados no livro La genèse du nombre chez l'enfant, publicado em 1941, definindo número como "a síntese da classificação e da seriação”.

No texto em questão apareceu, pela primeira vez, a resposta à pergunta: $\mathrm{O}$ que é número? Piaget e Szeminska se propuseram a apresentar, a partir de observações precisas, uma explicação teórica coerente da construção do número na infância. O interesse despertado pela obra, desde sua publicação, jamais diminuiu, apesar ou por causa das críticas teóricas que o livro contém e dos novos fatos experimentais nele apresentados.

Os sujeitos da pesquisa foram restritos a crianças do período intuitivo, não porque não existissem indicativos da presença do número em crianças mais jovens, mas porque toda análise metodológica necessita fixar "começos". Para não ficar remontando indefinidamente às origens, Piaget e Szeminska estabeleceram que os sujeitos de sua investigação deveriam ser capazes de realizar tarefas inerentes às provas cognitivas programadas, limitando-os, então, ao período intuitivo ou pré-operatório.

Para a determinação das provas, Piaget e Szeminska se fixaram nas principais "qualidades" ou "necessidades" do número para existir - a conservação de quantidades (condição de todo e qualquer conhecimento), a correspondência termo a termo (essencial para a contagem), a determinação da cardinalidade e do princípio ordinal (aspectos indissociáveis do número) - , e, em todas elas, é possível perceber que os autores buscam confirmar a hipótese, não colocada abertamente, de que o número é a síntese da classificação e da seriação.

Como Piaget e Szeminska formularam essa hipótese é o tema que investigamos, mediante pesquisa bibliográfica sobre a construção do número, objetivando compreender o contexto científico e filosófico no qual os pesquisadores estavam inseridos.

\section{O número pela história e pela filosofia: algumas consideraçôes}

Até o século 18, embora já inteiramente dedutiva, a matemática estava particularmente ligada aos algoritmos, e pouca ou nenhuma preocupação existia quanto à natureza de seus elementos ou quanto aos seus fundamentos. De uma maneira geral, à exceção do período clássico, na Grécia Antiga, a evolução das idéias matemáticas prosseguiu, até aí, de uma maneira praticamente linear, sem maiores revoluções. Esta história, vista hoje, parece indicar que a matemática se desenvolveu de uma maneira praticamente "esperada".

Tal não é, todavia, o panorama do século 19, no qual, após a descoberta de 
um novo mundo na geometria, a matemática passou a ser reconhecida não mais como uma ciência natural, decorrente da observação da natureza, ou que buscasse descrevê-la, mas como uma criação intelectual do homem. Em decorrência dessa nova concepção surgida no século 19, com o advento das geometrias não-euclidianas, a aritmetização da análise e da álgebra, a adoção da lógica simbólica como a linguagem da matemática e com a libertação da matemática do real, eclodiu o que ficou conhecido como "a crise dos fundamentos" da matemática. Surgiram então, como vamos descrever a seguir, diferentes formas de conceber a matemática e, conseqüentemente, diferentes definições para número.

\section{As principais correntes do pensamento matemático}

Por quase todo o século 19, o mito de Euclides (c.450-c.380 a.C.) era inabalável tanto para os filósofos como para os matemáticos. A geometria euclidiana era considerada por todos "como o mais firme e confiável ramo do conhecimento” (Davis; Hersh, 1986, p. 371).

A descoberta das geometrias nãoeuclidianas, contudo, implicou a perda da certeza da geometria, abalando, conseqüentemente, não só os alicerces da matemática, mas de todo o conhecimento. Os matemáticos do século 19 enfrentaram o problema e buscaram uma outra fonte segura para fundamentar seus trabalhos, elegendo a aritmética como a "nova base sólida”.

Ao alicerçar a matemática sobre a aritmética, porém, se estava, em última instância, fundamentando-a sobre o número natural, e verificou-se, então, que este não possuía uma definição matemática formalizada, a ponto de o alemão Kronecker (1823-1891) haver dito que "Deus fez os números inteiros, todo o resto é criação do homem” (Eves, 1995, p. 616).

Estava desencadeada a "crise dos fundamentos” na matemática.

A partir daí surgiram diversas correntes buscando soluções para os profundos problemas apresentados, soluções estas que se resumiam em tornar a matemática, novamente, uma ciência confiável. Dessas correntes, três se destacaram: o logicismo, o intuicionismo e o formalismo. Estas três correntes continuam, até hoje, a dividir os matemáticos quanto aos fundamentos da matemática.

\section{O logicismo}

O matemático alemão Friedrich Ludwig Gottlob Frege (1848-1925) acreditava que a solução para o impasse seria a redução da aritmética à lógica. Para realizar esta tarefa, pretendia efetivar a consecução de dois grandes objetivos: o primeiro seria definir toda expressão aritmética em termos lógicos e com isso mostrar que a toda expressão aritmética equivale uma expressão lógica determinada; caso conseguisse realizar tal tarefa, o segundo objetivo consistiria em mostrar que as proposições lógicas obtidas poderiam ser deduzidas de leis lógicas imediatamente evidentes.

Frege eliminou qualquer recurso à intuição e à linguagem comum, procurando mostrar que a aritmética poderia ser considerada como um ramo da lógica e que suas demonstrações não necessitavam se fundamentar nem na experiência e nem na intuição. Observou, então, que a matemática necessitava de uma profunda revisão crítica, como nunca acontecera antes. Acreditava que seriam necessárias demonstrações de proposições que, anteriormente, se aceitavam como evidentes e que conceitos relativamente novos, como de função, de contínuo, de limite, de infinito, etc., precisavam ser reexaminados. De maneira geral, seria necessário examinar todos os campos da matemática com o rigor de demonstração, delimitação precisa da validade dos conceitos e sua exata definição, a partir já do próprio conceito de número.

Além da perda de credibilidade da geometria como base sólida, é preciso recordar que, praticamente na mesma época, apareceram as várias antinomias da teoria dos conjuntos, abalando todo o edifício matemático e fortalecendo a idéia de Frege, de que apenas uma análise minuciosa dos fundamentos da matemática, "graças ao novo instrumento lógico, poderia salvar a coerência das matemáticas” (Grize, apud Piaget et al., 1980, p. 121).

O programa apresentado por Frege não encontrou eco até ser acatado por B. Russell (1872-1970) e A. Whitehead (1861-1947). Os dois retomaram a tese de Frege e procuraram demonstrar que a matemática pura (incluída aí a geometria) poderia ser inteiramente deduzida da lógica. 
Embora até então tivessem sido tratadas, historicamente falando, como estudos distintos, a matemática sempre relacionada com as ciências e a lógica com o idioma grego, o desenvolvimento de ambas, durante o século 19 e início do século 20, de acordo com Russell, aproximou definitivamente lógica e matemática, a lógica tornando-se cada vez mais matemática e a matemática, cada vez mais lógica, de maneira a ser, para Russell, inteiramente impossível traçar uma linha entre as duas; "na verdade, as duas são uma. Diferem entre si como rapaz e homem: a lógica é a juventude da matemática e a matemática é a maturidade da lógica” (Russell, 1974, p. 186).

A tese do logicismo é que a matemática é um ramo da lógica. Assim, a lógica, em vez de ser apenas um instrumento da matemática, passa a ser considerada como a geradora da matemática. Todos os conceitos da matemática têm que ser formulados em termos de conceitos lógicos, e todos os teoremas da matemática têm que ser desenvolvidos como teoremas da lógica; a distinção entre matemática e lógica passa a ser uma questão de conveniência prática. (Eves, 1995, p. 677).

\section{O formalismo}

O embrião da escola formalista foi um estudo postulacional realizado pelo matemático alemão David Hilbert (1862-1943) sobre a geometria, em 1899. Nesse estudo, Hilbert aprimorou o método matemático desde a axiomática considerada material, dos tempos de Euclides, à axiomática formal do século 20. Algum tempo depois, tentando solucionar a crise instaurada pelas antinomias na teoria dos conjuntos e para responder ao desafio à matemática clássica, estabelecido pelos intuicionistas, Hilbert dedicou-se, seriamente, à elaboração do programa formalista.

A tese do formalismo é que a matemática é, essencialmente, o estudo dos sistemas simbólicos formais. De fato, o formalismo considera a matemática como uma coleção de desenvolvimentos abstratos em que os termos são meros símbolos e as afirmações são apenas fórmulas envolvendo esses símbolos; a base mais funda da matemática não está plantada na lógica mas apenas numa coleção de sinais ou símbolos pré-lógicos e num conjunto de operações com esses sinais. Como, por esse ponto de vista, a matemática carece de conteúdo concreto e contém apenas elementos simbólicos ideais, a demonstração da consistência dos vários ramos da matemática constitui uma parte importante e necessária do programa formalista. Sem o acompanhamento dessa demonstração de consistência, todo o estudo perde fundamentalmente o sentido. Na tese formalista se tem o desenvolvimento axiomático da matemática levado a seu extremo (Eves, 1995, p. 682).

\section{O intuicionismo}

Embora não tenha sido ele matemático e nem tenha vivido a maior parte da sua vida no século 19, o pensamento filosófico de Immanuel Kant (1724-1804) influenciou profundamente o desenvolvimento científico e cultural dos séculos 19 e 20, inclusive o da matemática, de modo que é oportuno um breve interstício para algumas considerações acerca da posição da matemática no sistema kantiano.

Até Kant, tanto os filósofos racionalistas quanto os empiristas dividiam as proposições matemáticas em duas classes mutuamente excludentes e que esgotavam o universo das proposições: as analíticas, que englobam as verdades da razão e cuja negação conduz a não-contradições, e as empíricas ou não-analíticas, que expressam os fatos. Kant reapresentou o problema da classificação das proposições oferecendo uma outra: as proposições poderiam ser analíticas e sintéticas, e a principal diferença entre Kant e seus antecessores é que ele faz a distinção de duas classes de proposições sintéticas - as empíricas ou sintéticas $a$ posteriori e as sintéticas a priori, que não são empíricas.

As proposições matemáticas seriam, segundo Kant, sintéticas a priori, pois seriam as formas puras da intuição, o espaço e o tempo, que permitiriam fundamentar e legitimar os juízos sintéticos a priori (e também toda a matemática) expressando a especificidade da matemática. Em outras palavras, a matemática se referiria à realidade concreta, mas utilizaria, para apreendê-la, conhecimentos a priori de tempo e de espaço, o primeiro fundamentando o número e, conseqüentemente, toda 
a aritmética, e o segundo alicerçando a geometria.

Estas idéias, que exerceram enorme influência nos matemáticos no século 19, constituíram a base do intuicionismo de Poincaré.

Jules Henri Poincaré (1854-1912) é considerado o matemático mais importante do período transitório entre os séculos 19 e 20, e, de acordo com diversos historiadores, nenhum de seus contemporâneos dominou tanta diversidade de assuntos, enriquecendo todos eles. Interessou-se pelas geometrias não-euclidianas, mas, ao contrário do que depois se comprovou, de que todas possuíam o mesmo grau de veracidade, preocupou-se sobremaneira em investigar qual a "verdadeira geometria". Para Piaget isto pode ter sido o fato que impediu Poincaré de "descobrir" a Teoria da Relatividade.

Poincaré produziu mais de 500 artigos técnicos e mais de 30 livros, tendo sido também um dos principais e mais hábeis divulgadores da matemática e da ciência, mediante uma série de obras populares e semitécnicas, entre as quais se destaca $A$ ciência e a hipótese (1906), um texto de característica semipopular, em que apresenta uma "teoria da matemática na qual é sensível a influência de Kant” (Costa, 1971, p. 92).

Bastante influenciado pelo sistema kantiano, Poincaré, porém, não se contentava apenas com o fato de que os postulados matemáticos fossem juízos sintéticos a priori; era preciso, também, que os conceitos aos quais se referissem correspondessem a certas intuições materiais, intuições estas que seriam indispensáveis à construção da ciência. Assim, tal como em Kant, a matemática para Poincaré se apóia em "intuições", principalmente na de número, razão pela qual é considerado um dos "fundadores" do intuicionismo.

Para Poincaré, o número possui o duplo caráter de conceito puro e de forma intuitiva. É conceito puro enquanto esquema do conceito de grandeza, isto é, "a parte sem a qual não se pode passar da grandeza pura à sua imagem no espaço e no tempo". É forma intuitiva porque representa a seqüência aditiva de uma unidade a outra unidade e "realiza a síntese de um mesmo objeto no espaço e no tempo" (Costa, 1971, p. 93).

Poincaré concluiu que o princípio de recorrência é sintético, porque não se reduz à lógica do princípio da não-contradição, e a priori, porque só poderia ser provado mediante um número infinito de experiências, o que é impossível. Deste modo, Poincaré enxergou no método matemático um elemento intuitivo, e, para ele, "intuição", como o número, possuía o duplo sentido de "fonte de noções puras ou como instinto inventivo" (Costa, 1971, p. 94).

Como "fonte de noções puras", a intuição direciona o espírito para a noção de número inteiro e, como instinto inventivo, impulsiona o profundo trabalho do espírito na descoberta científica. Desta forma, para Poincaré, o número teria um caráter sintético e irredutível, enquanto para Russell, conforme será explicitado posteriormente, o número cardinal seria a "classe das classes". Isto retrata a oposição existente entre as correntes de pensamento matemático logicismo e intuicionismo, que, juntamente com o formalismo de Hilbert, pretenderam resolver a "crise dos fundamentos" no século 20 .

O intuicionismo de Poincaré ganhou força como corrente quando o holandês L. E. J. Brouwer (1881-1966) conseguiu reunir em torno das idéias intuicionistas os oposicionistas do formalismo de Hilbert e do logicismo de Russell. Para os seguidores do intuicionismo, os elementos e axiomas da matemática não são tão arbitrários como possam parecer. Segundo Brouwer (1974, p. 448), “a linguagem e a lógica não são pressuposições para a matemática, a qual tem sua origem na intuição que torna seus conceitos e inferências imediatamente claros para nós...”.

A tese do intuicionismo é que a matemática tem de ser desenvolvida apenas por métodos construtivos finitos sobre a seqüência dos números naturais, dada intuitivamente. Logo, por essa visão, a base última da matemática jaz sobre uma intuição primitiva, aliada, sem dúvida, ao nosso senso temporal de antes e, depois, que nos permite conceber um objeto, depois mais um, depois outro mais, e assim por diante, indefinidamente. Dessa maneira obtêm-se seqüências infindáveis, a mais conhecida das quais é a dos números naturais. A partir dessa base intuitiva (a seqüência dos números naturais), a elaboração de qualquer outro objeto matemático deve ser feita necessariamente por processos construtivos, mediante um número finito de passos ou operações. $\mathrm{Na}$ 
tese intuicionista o desenvolvimento genético da matemática é levado a extremos (Eves, 1995, p. 679).

Segundo Machado (1987), o intuicionismo considera a matemática como uma atividade autônoma, uma construção de entidades abstratas a partir da intuição dos matemáticos, e, como tal, prescinde tanto de uma redução à lógica quanto de uma formalização rigorosa em um sistema dedutivo, o que era defendido por Hilbert e seus seguidores.

Na transição do século 19 para o século 20, ocorreram muitos congressos internacionais de matemática (o primeiro foi em Chicago, em 1893). No segundo, realizado na cidade de Paris, em 1900, Hilbert proferiu a conferência principal, na qual apresentou uma lista com 23 problemas, que, segundo ele, seriam os focos das atenções dos matemáticos do século 20 . No mesmo congresso, Poincaré apresentou um trabalho em que comparava os papéis da lógica e da intuição na matemática. A partir desse congresso, Hilbert se envolveu, com Poincaré, em uma das maiores controvérsias do século.

Hilbert admirava o Mengenlehre de Cantor, ao passo que Poincaré o criticava fortemente. As teorias de Cantor, como os abstratos espaços de Hilbert, pareciam muito afastadas da base intuitivoempírica que Poincaré e alguns de seus contemporâneos preferiam (Boyer, 1974, p. 448).

Os matemáticos da época agruparamse em torno das três principais correntes de pensamento: o intuicionismo de Poincaré, o formalismo de Hilbert e o logicismo de Russell, esta última ligada ao formalismo (ambas valorizam a lógica), mas não identificada com ele.

Todavia, como o sucesso ou o fracasso do programa formalista estava vinculado à resolução do problema de consistência, o sonho dos seguidores do formalismo teve curta existência, pois, em 1931, o então jovem matemático Kurt Gödel (1906-1978), discípulo de Hilbert, provou de maneira inconteste, por seguidores das três principais correntes, que não é possível provar a consistência de um sistema dedutivo formalizado capaz de abranger toda a matemática clássica, com todos os seus princípios lógicos, conforme era idealizado por
Hilbert e seus seguidores. Desta forma, o debate acerca dos fundamentos da matemática se centralizou em torno do logicismo e do intuicionismo.

São estes, portanto, o cenário e o instrumental lógico de que dispunha Piaget quando realizou sua investigação sobre a construção do número.

\section{As principais concepções de número}

Como dissemos, no livro $A$ gênese do número na criança, Piaget e Szeminska queriam confirmar a hipótese, não explicitamente exposta por eles, de que a noção de número seria a síntese operatória da seriação e da classificação. Reafirmamos que esta hipótese estaria implícita, uma vez que, no prefácio, escrito em 1941, da edição francesa da referida obra, o pesquisador afirma que "foi unicamente o problema da construção do número em relação com as operações lógicas" que despertou o seu interesse (Piaget; Szeminska, 1981, p. 12).

Ainda no prefácio em questão, Piaget esclarece a hipótese que direcionou a pesquisa realizada:

\begin{abstract}
A hipótese da qual partimos é, obviamente, que esta construção é correlativa do desenvolvimento da própria lógica e que ao nível pré-lógico corresponde um período pré-numérico (Piaget; Szeminska, 1981, p. 12).
\end{abstract}

Os resultados a que chegaram Piaget e Szeminska (1981, p. 12) confirmaram que a hipótese por eles estabelecida, de que

[...] o número se organiza, por etapa, em solidariedade estreita com a elaboração gradual dos sistemas de inclusões (hierarquia das classes lógicas), com as relações assimétricas (seriações qualitativas) e com a sucessão dos números, constituindo-se, assim, em síntese operatória da classificação e seriação.

Todavia, uma análise mais acurada da investigação desenvolvida por Piaget e Szeminska nos permite inferir, uma vez que as provas estabelecidas parecem conduzir para isso, que a hipótese de que o número se constituiria a síntese da 
classificação e da seriação estava presente durante todo o desenvolvimento da pesquisa realizada. O que teria motivado Piaget a formular tal hipótese?

Para responder a esta pergunta, entra em cena o forte apelo epistemológico das soluções insatisfatórias para a questão "o que é número?”, particularmente o longo e antigo debate, sem vencedor, entre logicistas e intuicionistas. A este debate acrescentem-se as convicções de Piaget de que o conhecimento não está nem no sujeito (apriorismo, implícito no logicismo) e nem no objeto (empirismo, pano de fundo do intuicionismo), mas na interação entre ambos, uma interação particular que acontece internamente ao sujeito. Pode-se inferir, assim, que Piaget procurava uma solução intermediária entre Russell e Poincaré.

Dito de outra forma, do mesmo modo como a concepção de inteligência de Piaget pode ser considerada como um tertium entre o lamarckismo e o neodarwinismo, que a sua posição acerca da construção do conhecimento fica a meio-caminho entre o empirismo e o apriorismo, ele terminaria por considerar o número também como uma espécie de tertium entre Russell e Poincaré, ao "conceber como recíprocas e não mais unilaterais a relação entre a lógica e a aritmética” (Piaget; Szeminska, 1981, p. 13).

Para confirmar nossa hipótese, a de que Piaget estaria procurando finalizar o debate entre logicistas e intuicionista acerca da construção do número, nos apoiamos em considerações, discussões e argumentações do próprio Piaget sobre esses modelos teóricos, extraídas dos prefácios da primeira e da terceira edição francesa do livro A gênese do número na criança, e de estudos posteriores do autor, particularmente na obra Introducción a la epistemologia genética. 1. El pensamiento matemático.

\section{O número no logicismo de Russell e Whitehead}

Partidários da idéia de Frege, Russell e Whitehead tinham o ambicioso plano de "reduzir" a matemática à lógica. Assim, apresentaram a aritmética como um ramo da lógica pura. Para isso, o "plano" era "traduzir" os axiomas de definição do número natural estabelecidos pelo matemático italiano Giuseppe Peano (1858-1932) em termos puramente lógicos, e definiram número em termos de classes e de relações, com o aspecto cardinal sendo estabelecido pelas classes, e o ordinal, pelas relações assimétricas, porém de forma independente. Um outro fator que decorre dessa concepção é que os números se constituem isoladamente, a partir de classes independentes entre si, e, portanto, não existiria uma iteração que culminaria com a sucessão dos números inteiros. Para verificar se esta explicação era satisfatória, para Piaget (1975, p. 91) o problema se resumiria em "determinar se os processos formadores do número são ou não os mesmos a partir dos quais derivam as classes e as relações”.

A teoria de Russell e Whitehead para o número começa com a descrição do que é uma “classe de classes”. Ou seja, duas classes consideradas em sua extensão dão origem a uma mesma classe de classes se é possível estabelecer uma correspondência biunívoca entre seus elementos. O número cardinal é definido como estas "classes de classes”, e, assim, o número 1 é a classe de todas as classes unitárias, o número 2 é a classe de todos os pares possíveis, o número 3 é a classe de todas as ternas, etc. $\mathrm{O}$ número ordinal é igualmente constituído por meio de classes, só que de relações assimétricas "semelhantes", e esta "semelhança” é obtida também mediante uma correspondência biunívoca.

Apesar de estas "definições” terem sido aprovadas por muitos matemáticos e quase todos os lógicos, houve muitas objeções que podem ser agrupadas em duas vertentes: as que defendem a existência de um círculo vicioso e as que preconizam a existência de diferenças funcionais entre a classe lógica e o número.

\section{O intuicionismo de Poincaré e o número}

O maior crítico ao reducionismo lógico foi o francês Henri Poincaré. Ele denunciava a existência de um círculo vicioso, porque o número já estaria presente ao se estabelecer a correspondência biunívoca entre os objetos singulares. Ele argumentava que na "expressão ‘um' homem, etc., o objeto individual ou a classe singular já implica a presença do número 1" (Piaget, 1975, p. 92).

A contra-argumentação expunha que existe uma distinção entre o "um” lógico e 
o número 1, ou seja, o “um” lógico implicaria a "identidade” e não o número, da mesma forma como os termos lógicos "alguns", “todos” ou "nenhum” se referem apenas à pertinência ou não dos indivíduos a uma determinada classe.

Segundo Piaget (1975, p. 92), tanto Russell quanto seus adversários desencadearam um embate sem saída, ao argumentarem com identidades e classes isoladas, pois o atomismo lógico possibilitava a justificativa em ambas as direções. A “[...] identidade pertence tanto à matemática como à lógica intensiva”, sendo que a especificidade lógica ou matemática só é passível de ser determinada em função da "estrutura de conjunto da totalidade operatória onde se inserem os elementos”.

No que se refere à diferença funcional entre classe e número, fica claro que a função da classe, como é constituída por indivíduos que gozam de uma determinada propriedade, é a de identificar, ao passo que a do número (que necessita abstrair as qualidades) é a de diversificar; daí se conclui que são funções fundamentalmente heterogêneas. Entretanto, novamente, esse argumento só seria válido se aplicado às totalidades operatórias e não aos elementos isolados.

Piaget analisou a solução logicista estudando a natureza da correspondência biunívoca estabelecida para se criar as classes equivalentes, para verificar se ela é puramente lógica (qualitativa) ou se já introduz explicitamente o número.

Para Piaget, na correspondência biunívoca lógica ou qualitativa os elementos se correspondem univocamente em função de suas qualidades, como, por exemplo, quando se analisam as semelhanças entre dois objetos (ou conjuntos de objetos) e, para isto, se estabelece a correspondência entre uma parte de um com a parte semelhante no outro. Por considerarem apenas as qualidades, as correspondências qualitativas independem da quantificação.

A correspondência biunívoca qualquer ou matemática não é estabelecida em função das semelhanças qualitativas, mas associando um elemento qualquer de um dos conjuntos a um elemento também qualquer do outro, com a única condição de que cada elemento seja colocado em correspondência uma única vez, o que implica uma quantificação, pressupondo a unidade.
O problema da concepção de Russell residia no fato de ele utilizar a correspondência biunívoca matemática ao estabelecer sua “classe de classes”. Deste modo, não é puramente a classe que gera o número cardinal, mas uma classe já quantificada pela correspondência qualquer.

Assim, quando Russell constrói o número 12 e faz corresponder um a um os apóstolos de Jesus Cristo com os marechais de Napoleão, o apóstolo Pedro não é associado ao marechal Ney em virtude de suas qualidades comuns (como quando um biólogo põe em correspondência os pelos dos mamíferos com as penas dos pássaros), mas simplesmente enquanto um constitui uma unidade qualquer do primeiro conjunto e o outro uma unidade qualquer do segundo (Piaget, 1975, p. 94).

Quanto ao número ordinal concebido como classe de relações assimétricas semelhantes, a primeira questão que se apresenta é saber qual é a "semelhança" que intervém na constituição de duas (ou mais) classes de relações assimétricas semelhantes, e, analogamente ao número cardinal, novamente é o tipo de correspondência biunívoca que é o determinante.

Russell, ao não estabelecer na sua dupla redução estas distinções genéticas que conduzem a uma distinção correlativa na lógica entre as operações como tais, e não somente entre as classes e as relações isoladas, se encerra, assim, em dois círculos viciosos (Piaget, 1975, p. 95).

\section{Poincaré e a intuição racional do número}

Poincaré não concordava com a tese de que o número poderia ser reduzido à lógica das classes e das relações. Ele entendia o número como o produto de uma intuição racional (sintética a priori) e irredutível às operações lógicas. Criticava os matemáticos que se deixavam guiar simplesmente pela intuição, pois "na primeira investida fazem conquistas rápidas, mas algumas vezes precárias, como se fossem ousados cavaleiros na linha de frente" (Poincaré, 1995, p. 13).

De acordo com Poincaré, se no século 19 os matemáticos dividiam-se em duas 
correntes, uma que se apoiava na lógica e outra na intuição, uma releitura dos clássicos os enquadraria como intuicionistas. E mais, como a intuição não oferece o rigor e nem mesmo a certeza, foi necessária uma evolução na ciência matemática, evolução esta que a encaminhou para a lógica. Todavia, "para fazer aritmética, assim como para fazer geometria, é preciso algo mais que a lógica pura”, sendo a intuição este "algo mais", ressaltando contudo que, sob esta denominação, diversas idéias estão subentendidas (Poincaré, 1995, p. 18).

A intuição se apresenta, pois, sob diversas formas, como um apelo aos sentidos e à imaginação; como generalização, por indução de procedimentos das ciências experimentais (representar um polígono de n lados, por exemplo) e, a que interessa particularmente a este trabalho, a intuição do número puro (princípio da indução) e da qual se originaria, para Poincaré, o verdadeiro raciocínio matemático, a única intuição que é passível de certeza.

A concepção de que o número (e, conseqüentemente, a matemática) é produto de uma intuição racional foi (e ainda é) sustentada por inúmeros matemáticos, existindo, porém, divergências quanto ao sentido de intuição, que varia desde "a intuição da essência estática do número até a intuição operatória” (Piaget, 1975, p. 95).

Ao considerar que o número inteiro se funda sobre uma intuição sintética $a$ priori que se traduz no raciocínio por indução ou recorrência, Poincaré, por mais convencionalista que tenha sido em muitas questões, como, por exemplo, sobre os vários tipos de números ou sobre os relacionamentos entre os diversos tipos de espaço, admite que tal intuição é operatória, ou seja, uma intuição isenta de contradição e que é "construída”.

A discordância de Piaget com os intuicionistas se fundamentava no fato de que a intuição do número puro não é a de um número específico e sim de um número qualquer, e seria, segundo o próprio Poincaré (1943, p. 37), a "faculdade de conceber que uma unidade pode agregar-se a um conjunto de unidades".

Assim, ao procederem de uma intuição que contém, de antemão, a noção de unidade, as operações numéricas se colocariam em oposição às operações lógicas. Entretanto, os resultados de inúmeras pesquisas realizadas por Piaget e outros sobre a gênese dos conceitos matemáticos mostram que:

Todos os conceitos de caráter extensivo e métrico como a medida, a proporção em geometria e o próprio número somente se constituem em sua forma operatória quando podem se apoiar em agrupamentos lógicos de caráter intensivo (Piaget, 1975, p. 96).

Isto não significa, porém, que exista um estádio caracterizado por estruturas lógicas, que poderia ser considerado pré-numérico, seguido de um estádio numérico; ao contrário, existe uma interdependência entre o lógico e o numérico e que é originária do conceito de conservação dos conjuntos como totalidades, sejam tais totalidades lógicas ou numéricas. E mais, esta conservação não se apresenta, absolutamente, como uma "intuição", mas é construída, operatoriamente, num longo e complexo processo.

A faculdade de conceber que uma unidade pode agregar-se a um "conjunto de unidades”, que é assinalado por Poincaré como sendo o específico da intuição do número puro, supõe, então, a "faculdade" de conceber conjuntos invariantes encaixados uns nos outros e a "faculdade" de ordenar desde o início os elementos agregados (Piaget, 1975, p. 97).

No entanto, se a sucessão dos números não pode se apoiar em uma primeira intuição contendo de antemão a idéia de unidade, após sua construção, esta mesma sucessão produz uma intuição racional, em tudo semelhante à descrita por Poincaré, à diferença, porém, de ser final e não prévia,

[...] no sentido de que o número é apreendido diretamente pelo espírito sem ser intermediado por raciocínios discursivos ou lógicos. [...] concentração instantânea de inumeráveis raciocínios anteriores (e esquecidos), esta intuição final é apenas a expressão da compreensão inteligente e não nos informa nada quanto à sua construção (Piaget, 1975, p. 98).

Piaget considerou que a intuição operatória do número puro, irredutível à lógica concebida por Poincaré, carecia de especificidade, enquanto que a redução de Russell não seria operatória o suficiente, e sua hipótese, então, é a de que haveria a 
possibilidade de um tertium entre as duas posições.

Sabe-se bem, com efeito, quantas discussões o problema das relações entre o número e a lógica ocasionou, com os logísticos procurando, com Russell, conduzir o número cardinal à noção de "classe de classes" e o número ordinal, dissociado do primeiro, à de classe de relações, enquanto seus adversários mantinham, como $\mathrm{H}$. Poincaré e L. Brunschvicg, o caráter sintético e irredutível do número inteiro. É verdade que nossa hipótese, num certo sentido, permite escapar a essa alternativa, porque se o número é classe e relação assimétrica ao mesmo tempo, ele não deriva de tal ou qual das operações lógicas particulares, mas somente da sua reunião, o que concilia a continuidade com a irredutibilidade e leva a conceber como recíprocas e não mais como unilaterais as relações entre a lógica e a aritmética. Delas não convinha menos verificar sobre o próprio terreno logístico as conexões assim estabelecidas pela experimentação psicológica, e foi o que logo tentamos (Piaget, 1981, p. 13).

\section{Conclusões}

Pode-se afirmar que, com Piaget e Szeminska, o número tem por fonte a lógica, porém não deriva de nenhuma operação em particular. O número é construído das relações de classes quando os sujeitos agrupam objetos por suas semelhanças, das relações assimétricas quando estabelecem as diferenças ordenadas e do número quando os sujeitos agrupam os objetos, ao mesmo tempo, como equivalentes e distintos, o que é conciliatório com a irredutibilidade de Poincaré.

Entendendo a importância das duas concepções de número, o intuicionismo e o logicismo, e a impossibilidade da supremacia de uma delas, pois ambas apresentavam aspectos positivos e negativos, Piaget deduziu que, em vez de serem contraditórias ou opostas, as duas concepções deveriam ser complementares. Dessa análise de Piaget e Szeminska, acreditamos, emergiu a hipótese de que o número seria a síntese da classificação e da seriação, demonstrada no livro A gênese do número na criança.

\section{Referências bibliográficas}

BOYER, C. B. História da matemática. São Paulo: Edgard Blücher, 1974.

COSTA, A. A. As idéias fundamentais em matemática e outros ensaios. São Paulo: Edusp, 1971.

DAVIS, H.; HERSH, R. A experiência matemática. Rio de Janeiro: Francisco Alves, 1986.

EVES, H. Introdução à história da matemática. Campinas: Unicamp, 1995.

PIAGET, J. et al. Lógica e conhecimento científico. Minho, Portugal: Barcelos, 1980.

. Introducción a la epistemologia genética. 1. El pensamiento matemático. Buenos Aires: Paidos, 1975.

PIAGET, J.; SZEMINSKA, A. A gênese do número na criança. 3. ed. Madrid: Aguillar, 1981.

POINCARÉ, H. La sciense et l'hypothèse. Paris: Flammarion, 1943.

RUSSELL, B. Introdução à Filosofia da Matemática. Rio de Janeiro: Zahar, 1974.

Clélia Maria Ignatius Nogueira é professora doutora do Programa de Pós-Graduação em Educação para a Ciência e Ensino da Matemática da Universidade Estadual de Maringá (UEM).

Recebido em 3 de julho de 2006.

Aprovado em 21 de julho de 2006. 